\title{
THE RESPIRATION OF STREPTOCOCCUS PYOGENES
}

\section{The Inhibition of Respiration and Growth by Sulf- ANILAMIDE; THE INHIBITION OF RESPIRATION BY HYDROXYL- amine and Its Sulfonamide and Other Derivatives ${ }^{1}$}

\author{
M. G. SEVAG AND MYRTLE SHELBURNE \\ Department of Bacteriology, School of Medicine, University of Pennsylvania, \\ Philadelphia
}

Received for publication June 12, 1941

\section{INTRODUCTION}

The therapeutic properties and growth-inhibiting effects of sulfonamide drugs on bacteria have been studied extensively and are well known. The type and number of reactions as well as other conditions involved in the processes of bacterial multiplication in animal systems and in vitro are so numerous and complex that it is difficult to gain a clear insight as to the mechanism of the action of these drugs. In contrast, a study of the drug effect on relatively simple biological processes, known to be essential for bacterial and other cell multiplication, can be analyzed and understood. The measurement of the oxygen uptake and carbon dioxide evolution in the presence of foodstuffs of high energy content through the intermediation of bacterial enzymes is suited for such a study. Furthermore, as these processes provide the cells with energy requisite for growth, measurable inhibition of these processes by these drugs supplies us with clues regarding certain of the possible modes of their action.

Barron and Jacobs (1937) studied the effect of $0.01 \mathrm{M}$ sulfanilamide on the oxidation of glucose by washed suspensions of hemolytic streptococci, Escherichia coli, Friedländer bacilli, and gonococci. They reported 7.9 per cent inhibition with streptococci, none with $E$. coli and gonococci, and 12.1 per cent inhibition with Friedländer bacilli. The maximum error being 5 per cent, a slight inhibiting effect was stated to have been demonstrated. Chu and Hastings (1938) studied the effect of 0.66

1 This work has been supported by a grant from The Commonwealth Fund. 
gram per cent sulfanilamide on the oxidation of glucose, $\left(\mathrm{O}_{2}\right.$ uptake), by washed suspensions of hemolytic streptococci, gonococci, pneumococci Type I and III, and meningococci. The experiments with streptococci were unsuccessful because the oxygen uptake was negligible under the experimental conditions they used. Gonococcus (24-29 $\mathrm{cmm} . \mathrm{O}_{2} / \mathrm{hr}$./mgm.) and meningococcus $\left(13-24 \mathrm{cmm} . \mathrm{O}_{2} / \mathrm{hr}\right.$. $/ \mathrm{mgm}$.) were poor respirers. Three experiments each with type I and III pneumococci (127-147 cmm. $\mathrm{O}_{2} / \mathrm{hr}$./mgm.) were reported. With type $\mathrm{I}$ in one experiment there was no inhibition, in the second and third experiments the inhibitions were 13 and 23 per cent. With type III two experiments showed no inhibition and in the third 27 per cent inhibition was demonstrated.

Whereas the above investigators experimented with washed suspensions of bacteria, we have tried to simulate the respiratory conditions in vivo by the addition of yeast extract, with or without serum, or defibrinated whole blood.

Bliss and Long (1939) reported that sulfanilamide and sulfapyridine inhibited the anaerobic growth of streptococcus C203. Broh-Kahn (1939) working with $E$. coli, confirmed their findings. Kalmanson (1940) reported that sulfanilamide in a concentration of $20 \mathrm{mgm}$. per cent was able to sterilize small inocula of streptococcus, strain C203 in 48 hours aerobically and anaerobically. The inhibiting effect of sulfanilamide on the anaerobic respiration of streptococcus to our knowledge has not been studied previously. In the present study this aspect of the problem has been investigated in parallel with the aerobic respiration. ${ }^{2}$

In parallel with $\mathrm{p}$-aminobenzenesulfonamide the effect of $\mathrm{p}$-hydroxylaminobenzenesulfonamide, p-aminobenzenesulfonhydroxyamide, benzenesulfonhydroxamide, benzhydroxamic acid, and hydroxylamine on the aerobic and anerobic respiration of streptococci was studied. This comparative study was made in the hope that valuable data might be forthcoming as to what particular

\footnotetext{
2 Coggeshall (1940) reported that the oxygen consumption of Plasmodium knowlesi (100 million parasites) was markedly reduced in a system containing $20 \mathrm{mg}$. of sulfanilamide. There was no observable effect on the $P$. inui parasites. The anaerobic $\mathrm{CO}_{2}$ production of both parasites was unaffected by sulfanilamide.
} 
structural characteristics exercise the highest antistreptococcal activity.

Since it has been assumed that some of the drugs undergo changes both in the animal system and in vitro in order to manifest their therapeutic properties, the behavior of the above-mentioned drugs per se was also studied under conditions employed for the measurement of respiration. Certain of these drugs were found to consume oxygen and certain others to liberate a gas not absorbable by potassium hydroxide. These changes were measured accurately and corrected for in evaluating our findings. The results presented in tables 1 and 2 and the percentage inhibitions cited in the text represent the corrected values.

\section{INHIBITION EXPERIMENTS}

\section{1. $p$-Aminobenzenesulfonamide}

The results of the inhibition experiments on the respiration of streptococci with this drug are given in tables 1 and 2. These show that sulfanilamide inhibits the aerobic and anaerobic respiration of streptococci. Mayer (Mayer and Oechsin, 1937; Mayer, $1937 \mathrm{a}$ and b; Mayer, 1939) advanced the hypothesis that this substance is oxidized in the animal body and in vitro to p-hydroxylaminobenzenesulfonamide which is responsible for the chemotherapeutic and growth-inhibiting property. In our experiments, sulfanilamide per se does not consume oxygen in aerobic systems and does not evolve any gas in anaerobic systems. The possible oxidation of this drug in defibrinated whole blood in the presence and absence of glucose was also investigated. In no case did we observe oxygen uptake by the drug itself. Our experimental findings under these conditions do not support the above assumption as applied to in vitro conditions.

Experiments correlating the effect of sulfanilamide on respiration and growth. Whether the inhibition of the aerobic and anaerobic respiration by sulfanilamide and similar drugs has a direct bearing on the growth-inhibiting effect and therapeutic property of these drugs is a natural question. We have tried to obtain the answer to this question experimentally. After a period of three hours of 


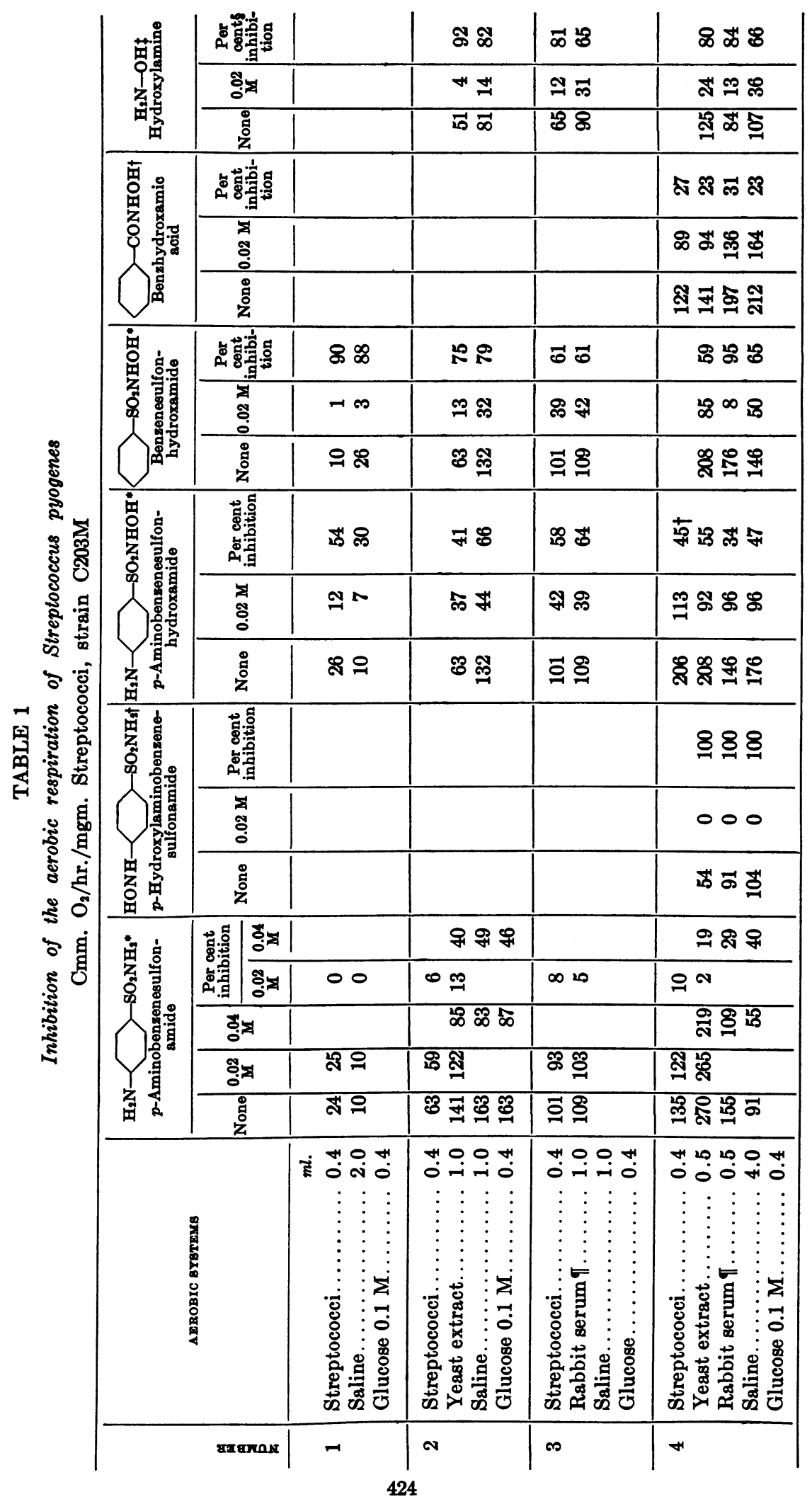




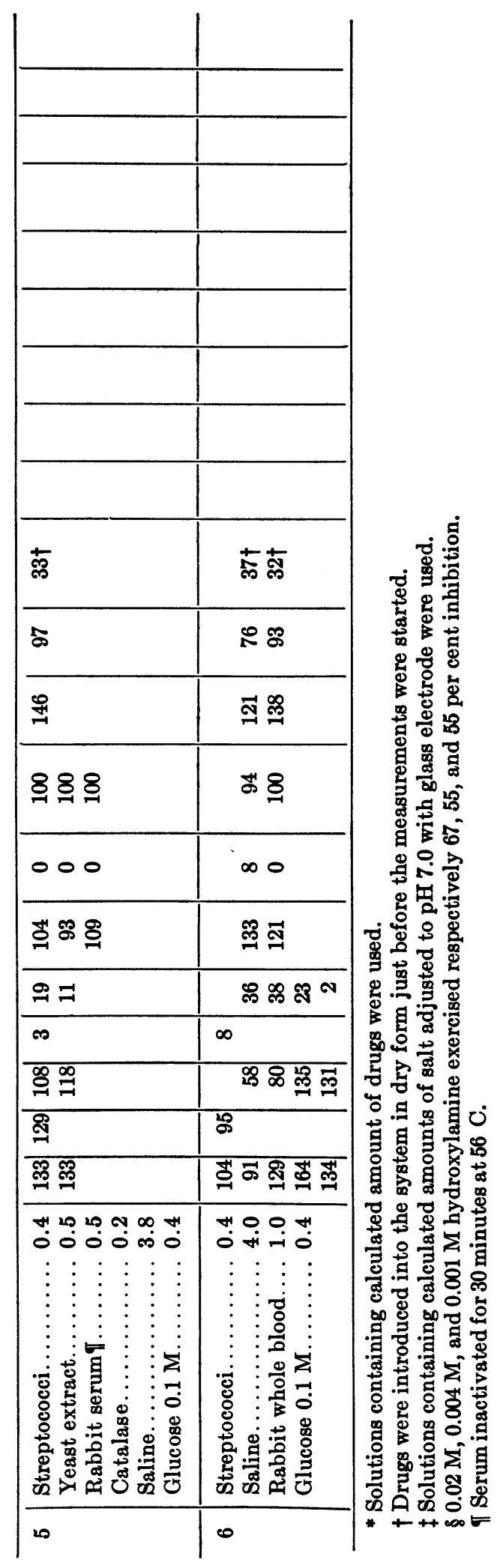




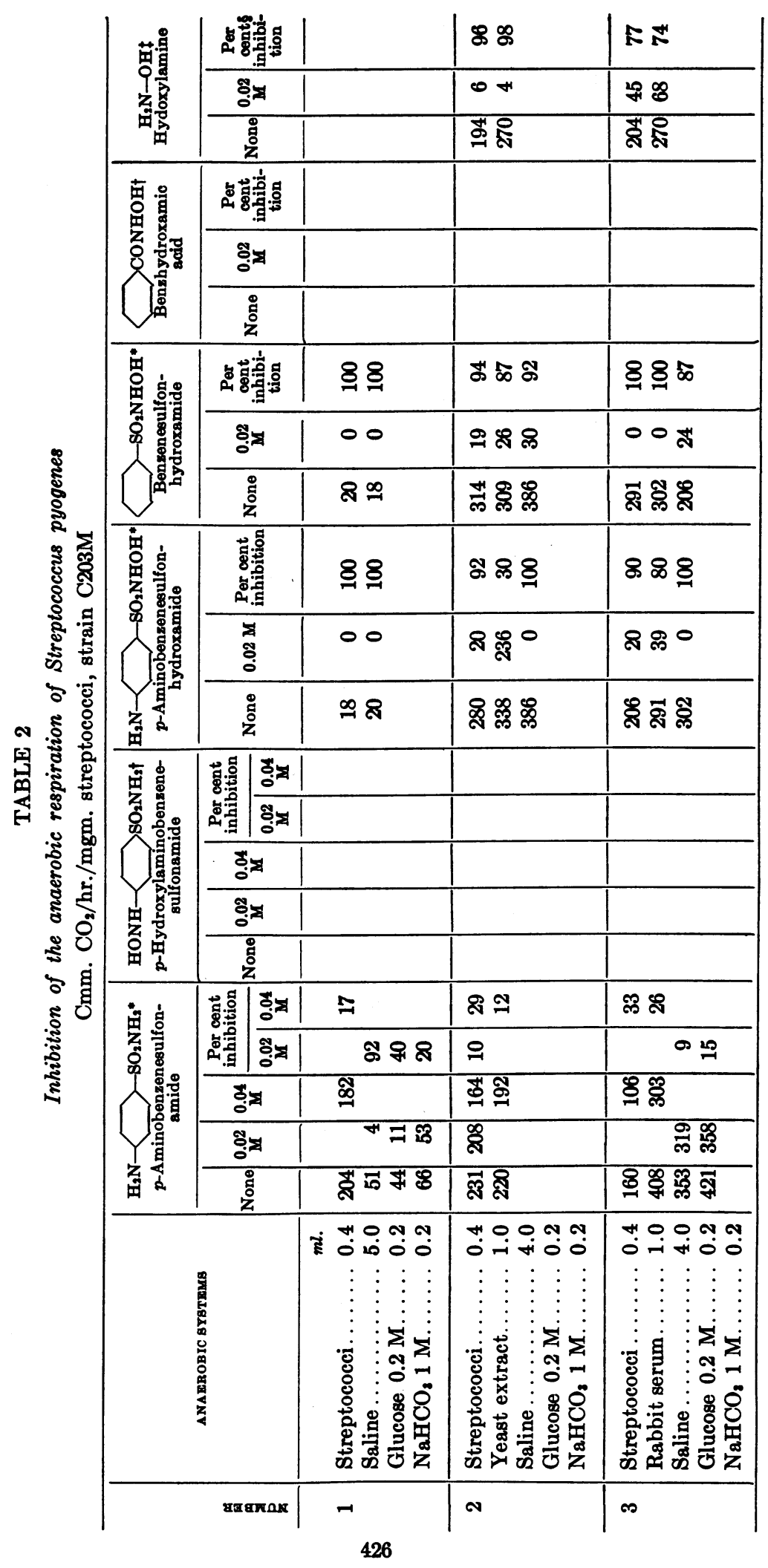




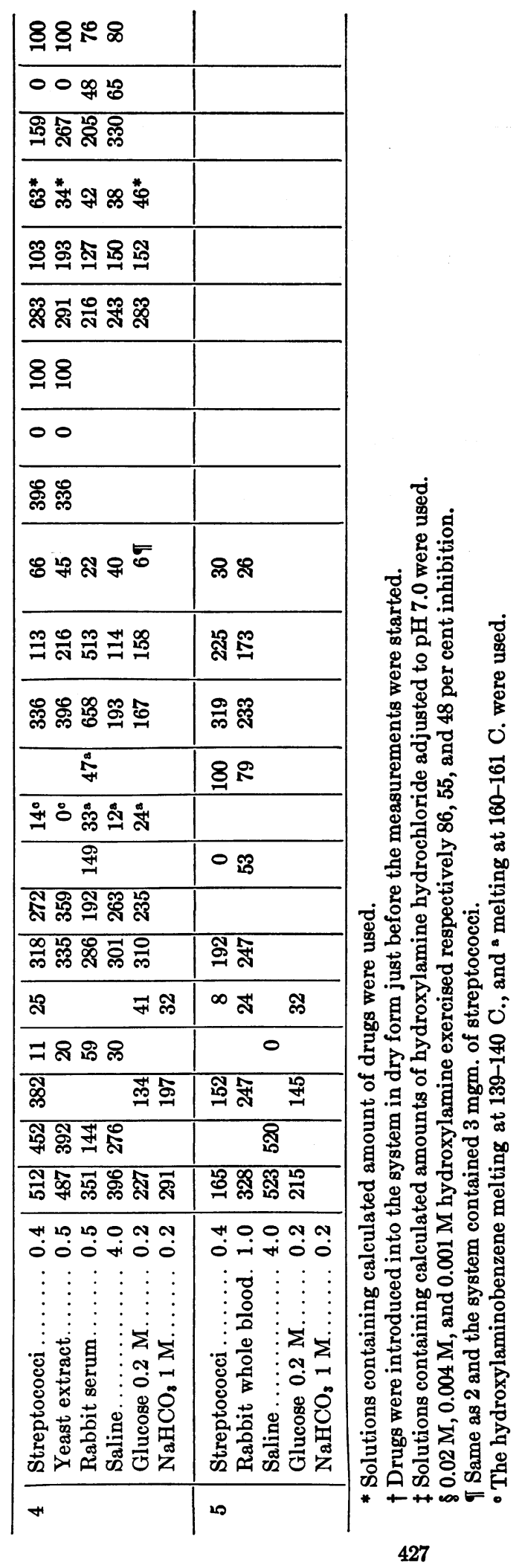




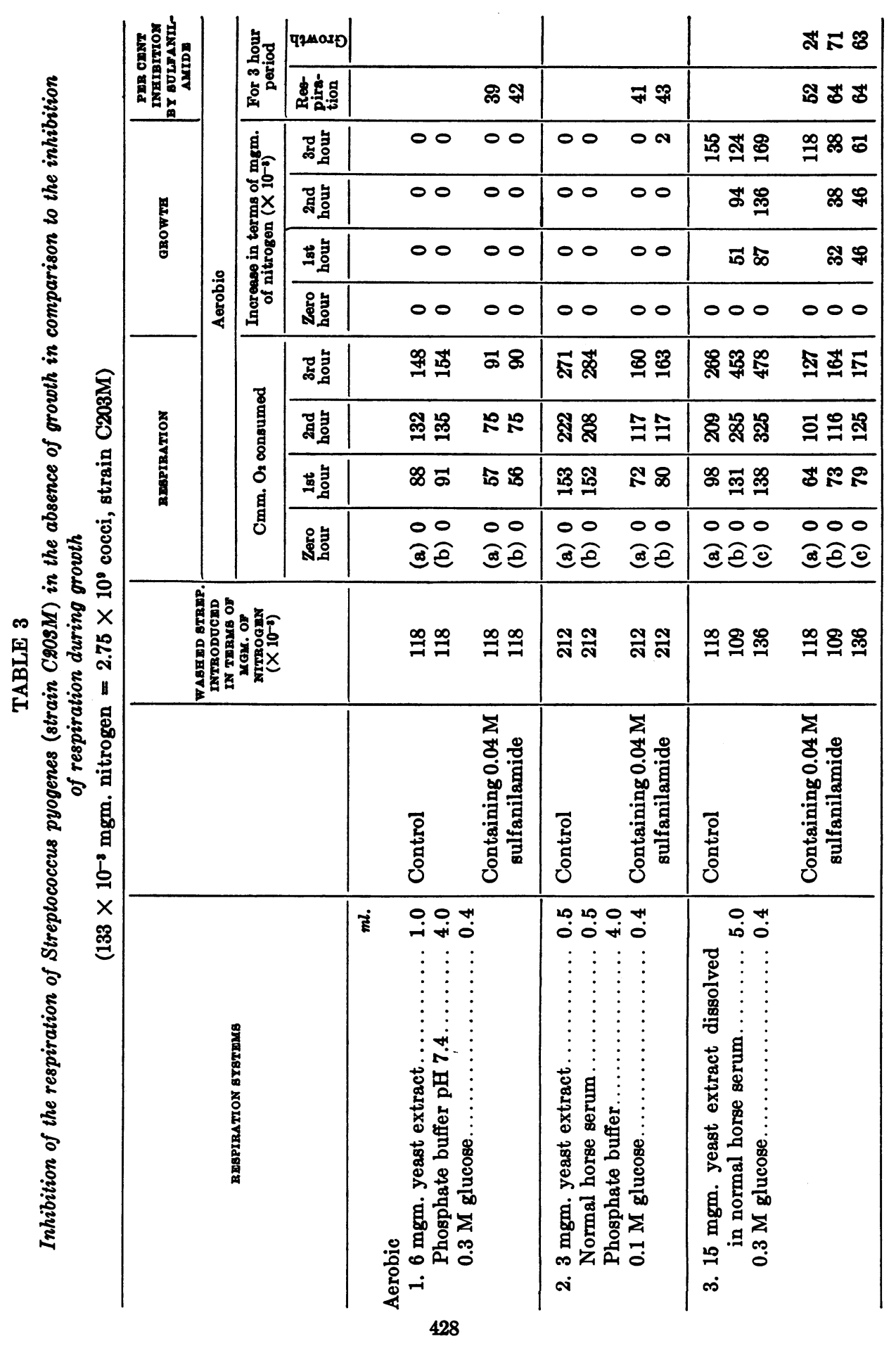




\begin{tabular}{|c|c|c|c|c|c|c|c|c|c|}
\hline \multirow{2}{*}{ 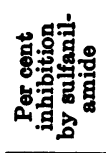 } & \multirow{2}{*}{ 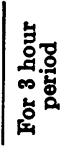 } & чұмого & \multirow{2}{*}{\multicolumn{2}{|c|}{ สి }} & \multicolumn{2}{|r|}{$*$} & \multicolumn{2}{|r|}{ 求宋尔 } & \multirow{5}{*}{ 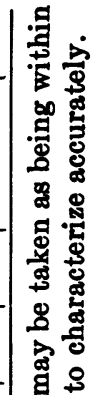 } \\
\hline & & 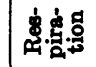 & & & & மே & & 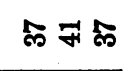 & \\
\hline \multirow{8}{*}{$\begin{array}{l}\circ \\
0 \\
0 \\
0\end{array}$} & \multirow{4}{*}{ 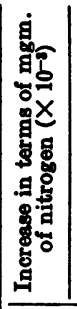 } & & 00 & 00 & $\stackrel{9}{9}$ & 00 & 8 & $88 \div$ & \\
\hline & & & 00 & 00 & $\infty 9$ & 00 & $\mathscr{\infty}$ & 荄 路 & \\
\hline & & & 00 & 00 & $\infty \infty$ & $\infty 0$ & $\infty$ & $20 \pi$ & \\
\hline & & & 00 & 00 & 00 & 00 & 000 & 000 & \multirow{7}{*}{ 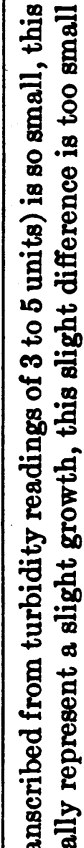 } \\
\hline & \multirow{4}{*}{ 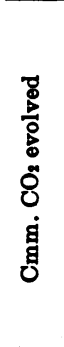 } & & 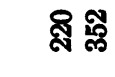 & छ유 & 电 & 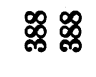 & 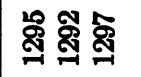 & 車员 & \\
\hline & & & ஓ ஜ ஜ & 茎 శ్సి & $\vec{\circ} \not$ & 必 శ్ & 용유 & 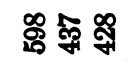 & \\
\hline & & & 冚 & 总 苟 & sొ & 命营 & ళ్లి స్లి శ్ & 莤嵒 & \\
\hline & & & $\begin{array}{l}00 \\
\text { ఏ2 }\end{array}$ & $\begin{array}{l}00 \\
\text { ब्र }\end{array}$ & 웅요 & $\begin{array}{l}00 \\
\text { ఏీ }\end{array}$ & 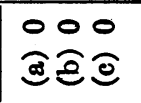 & 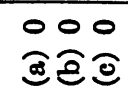 & \\
\hline & & & $\stackrel{\infty}{\sharp} \stackrel{\infty}{=}$ & $\stackrel{\infty}{\Rightarrow} \stackrel{\infty}{=}$ & ざ & త゙๋ & $\stackrel{\infty}{=} 8$ & $\stackrel{\infty}{=} 8$ & \\
\hline & & & Dृ & 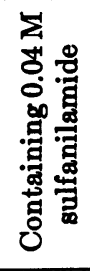 & 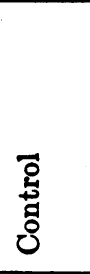 & 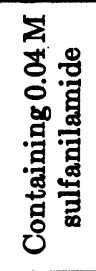 & 苞 & 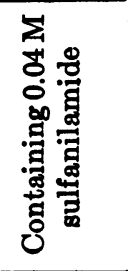 & \\
\hline & & & 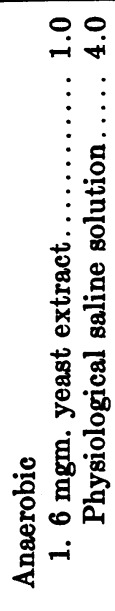 & 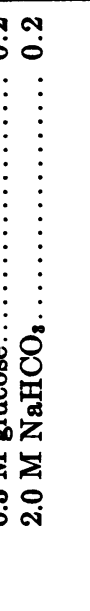 & 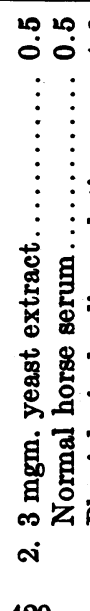 & 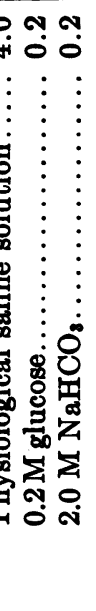 & 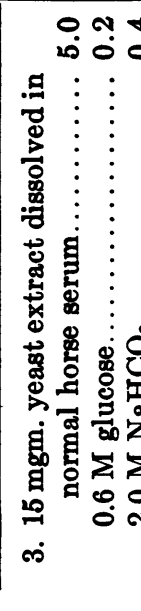 & & 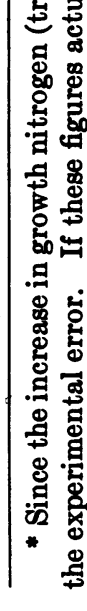 \\
\hline & & & & & 429 & & & & \\
\hline
\end{tabular}


active respiration of $2.7 \times 10^{\circ}$ washed organisms in the presence of small quantities of yeast extract, glucose, and serum, there was no measurable increase in the number of organisms over that of the initial number (table 3). This was determined by making turbidity measurements with a Klett-Summerson photoelectric colorimeter as described below. A possible explanation might be that the food is attacked and energy liberated as shown by the $\mathrm{O}_{2}$ and $\mathrm{CO}_{2}$ exchange, but that this energy is not utilized because in an environment with limited amount of nutrient such a large number of organisms could not multiply. It is also possible that the increase in the number of organisms was too small to detect by this method.

Ely (1939) in a similar experiment with $E$. coli studied the oxygen consumption in a synthetic medium. He stated that there was considerable growth in this medium when small inocula were used. However, in suspensions of the concentrations used $(3.5 \times$ $10^{\circ}$ to $4.5 \times 10^{\circ}$ organisms per ml.) a rather rapid and uniform respiration occurred with no increase in population as determined by the plate counting method.

In our subsequent experiments the serum, yeast extract, and glucose content of the systems were considerably increased (see table 4). Then aerobic and anaerobic respiration and growth were measured in the presence and absence of sulfanilamide. The growth was estimated by determining the increase of turbidity, after 1,2 , and 3 hours of respiration, by means of the photoelectric colorimeter.

Twelve Warburg vessels were used, one vessel for each determination. The content of each vessel was washed out completely into a standard tube and brought to a definite volume before turbidity readings were taken. The weight of organisms introduced into each system was determined at the start by determining the total nitrogen content and turbidity values of the measured samples. The readings on the apparatus were calibrated by nitrogen values of the suspensions of various concentrations. The range of turbidity readings, from 0 to 240 , plotted against the total nitrogen values ranging from 0.053 to $0.953 \mathrm{mgm}$. nitrogen, was a straight line. 
TABLE 4

Correlation of the inhibition of aerobic ( $\mathrm{cmm} . \mathrm{O}_{2}$ consumed) and anaerobic ( $\mathrm{cmm}$. $\mathrm{CO}_{2}$ evolved) respiration with the inhibition of the aerobic and anaerobic growth by sulfanilamide

$\left(133 \times 10^{-8} \mathrm{mgm} . \mathrm{N}=2.75 \times 10^{\circ}\right.$ cocci, strain C203M)

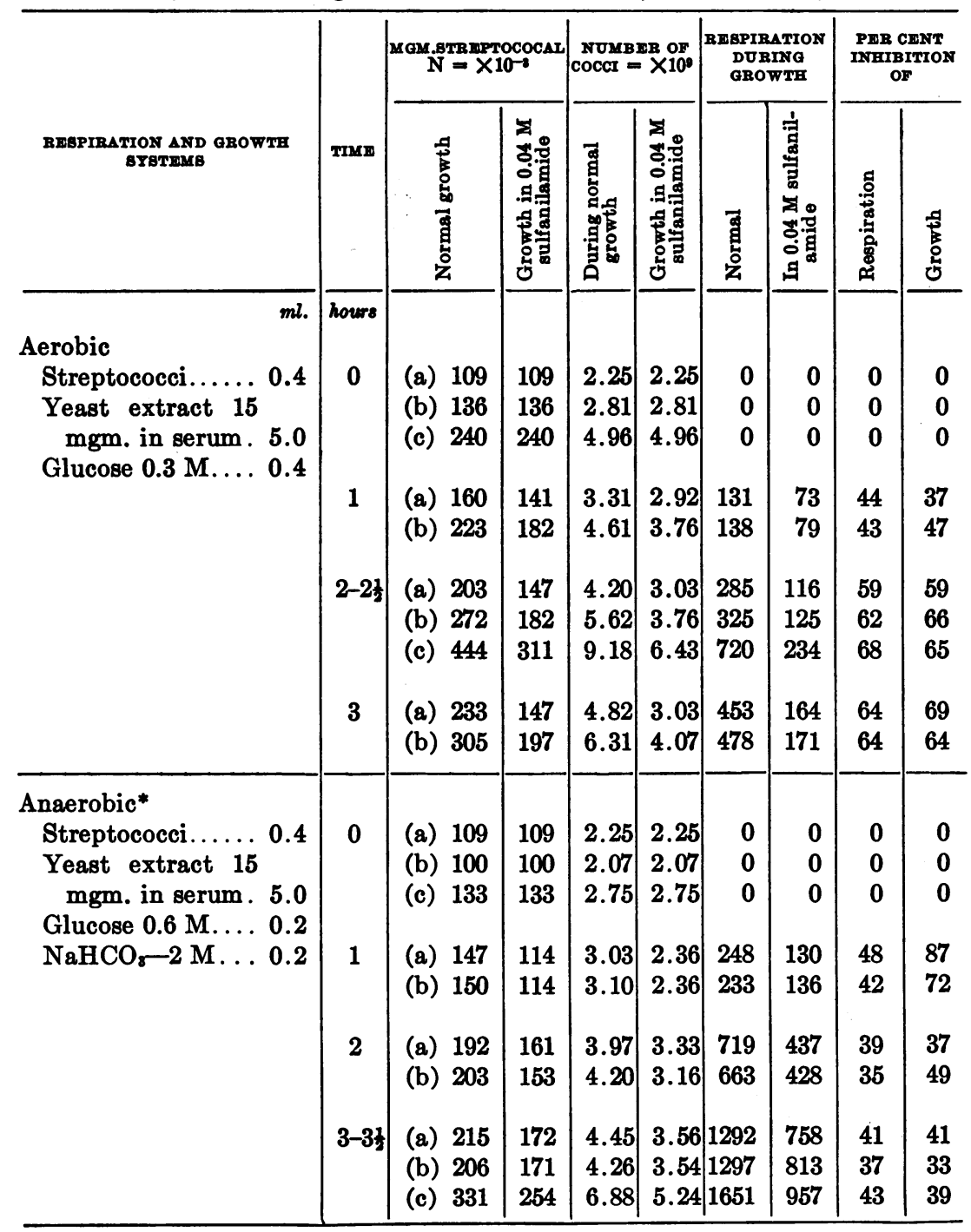

$* 5 \% \mathrm{CO}_{2}+95 \% \mathrm{~N}$. 
The results of both respiration and growth measurements with the same streptococcal suspensions are given in table 4 and in figures 1 and 2. The data show that the inhibition of respiration
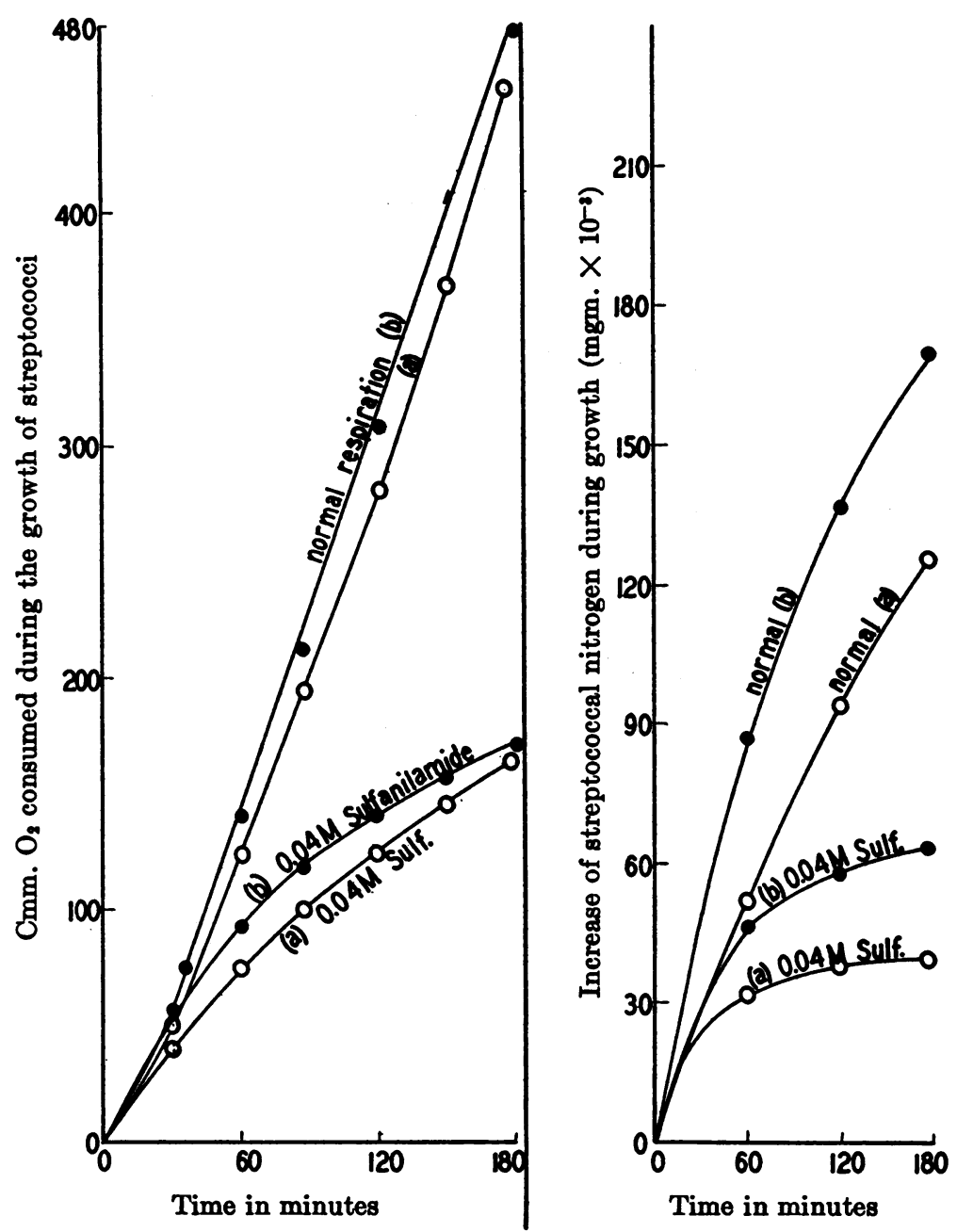

Fig. 1. Corremation of the Inhibition of Atrobic Respiration and Growth

results in the inhibition of growth aerobically and anaerobically. The degree of the inhibition of respiration is of the same order of magnitude as the inhibition of growth by sulfanilamide. 

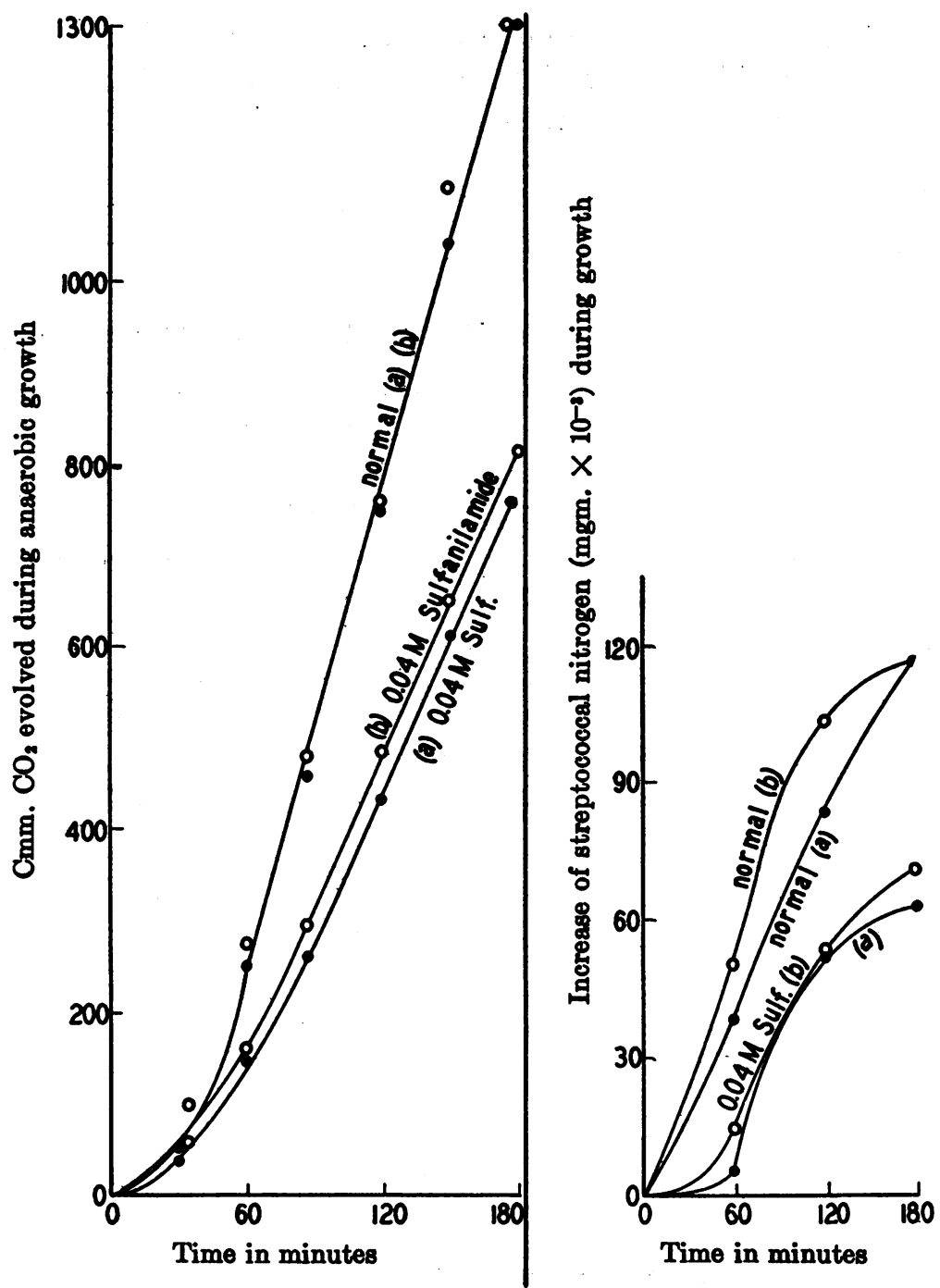

Fig. 2. Corrmlation of the Inhibition of anatrobic Rigpiration and GROWTH

\section{2. $p$-Hydroxylaminobenzenesulfonamide}

Mayer reported that $\mathrm{p}$-hydroxylaminosulfonamide is 100 times more effective in vitro than sulfanilamide. Bratton, White, and Marshall (1939) on the other hand reported that in in vitro experi- 
ments it was 10 times more effective than sulfanilamide. These investigators did not take into consideration the toxic effect of hydrogen peroxide which results from the oxidation of hydrox-

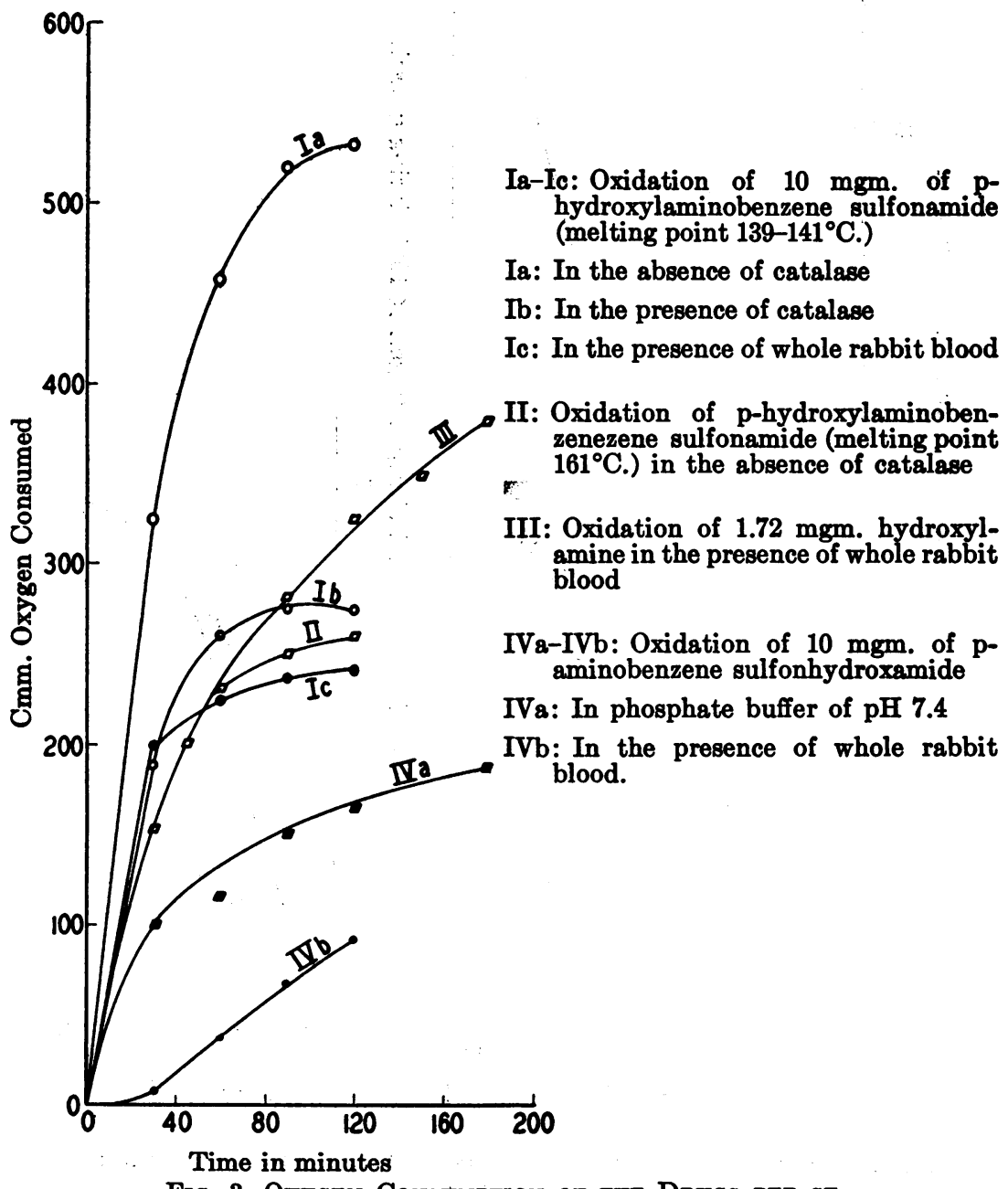

Fig. 3. Oxygen Consumption of the Druas Per se

ylaminosulfonamide in in vitro experiments in the absence of catalase. Furthermore the discrepency between Mayer's findings and those of the latter group appears to be due to the fact that Mayer used a hydroxylaminosulfonamide melting at $161^{\circ} \mathrm{C}$. and the others experimented with the one melting at 139.5 to $140.5^{\circ} \mathrm{C}$. 
Our findings show that the higher melting point substance is more resistant to air oxidation and perhaps for that reason exercises greater inhibition on the respiration than the one with the lower melting point (fig. 3, Ia, II).

p-Hydroxylaminobenzenesulfonamide inhibits completely the aerobic respiration of streptococci in blood, and in serum and yeast extract mixture after elimination of hydrogen peroxide by catalase (table 1). Anaerobic respiration in blood is inhibited 80 to 100 per cent, and in serum and yeast extract 15 to 50 per cent (table 2). The reaction products of oxidation of hydroxylaminobenzenesulfonamide are hydrogen peroxide and probably azoxydibenzenesulfonamide (Bamberger, 1898, 1900). Experiments were carried out to determine the inhibiting effect of the oxidation product on respiration. One ml. of a 1 per cent solution was allowed to oxidize completely in the Warburg apparatus. When the system ceased to use oxygen the resulting hydrogen peroxide was eliminated by catalase and the effect of the reaction mixture was tested on respiration. The oxidation product free of hydrogen peroxide, was only 25 per cent effective in aerobic respiration in contrast to 100 per cent inhibition obtained with the dry drug introduced just before the measurements started. The oxidation product was without inhibiting effect on the anaerobic respiration of streptococci.

Properties of the drug. Part of the p-hydroxylaminobenzenesulfonamide used in our experiments was kindly supplied by Dr. R. O. Roblin, Jr. of the American Cyanamide Company. It was crystalline and melted at 139.5 to $140.5^{\circ} \mathrm{C}$. Our preparation (preparation C) prepared according to the method of Bratton, White and Marshall (1939) was also crystalline and melted at 139 to $140^{\circ} \mathrm{C}$. A second crystalline substance prepared by a modified method melted at 160 to $161^{\circ} \mathrm{C}$. (preparation A), which corresponds to that reported by Mayer. Both of these were prepared from the same p-nitrobenzenesulfonamide. In what other respects these two substances differ will be discussed in another communication. It will suffice to state at present that they appear to be isomers. ${ }^{3}$

${ }^{3}$ While this paper was in press, Burton (1941) reported (June 14, 1941) the preparation of two p-hydroxylaminobenzenesulfonamides, one melting at 139$140^{\circ}$, the other at $160-161^{\circ}$. Our preparations seem to be similar. However, 
Both preparations are quite stable in anaerobic systems. They oxidize readily in aerobic systems. In studies to determine their effect it is essential that the drug be kept dry and introduced from the side arm into the respiration system just before the measurements are started.

It has been shown that the solutions of hydroxylaminobenzenes oxidize in the following manner (Bamberger, 1898, 1900):

$$
\begin{aligned}
\mathrm{C}_{6} \mathrm{H}_{5} \mathrm{NHOH}+\mathrm{O}_{2} & \longrightarrow \mathrm{C}_{6} \mathrm{H}_{6} \mathrm{~N}=\mathrm{O}+\mathrm{H}_{2} \mathrm{O}_{2} \\
\mathrm{C}_{6} \mathrm{H}_{6} \mathrm{~N}=\mathrm{O}+\mathrm{C}_{6} \mathrm{H}_{6} \mathrm{NHOH} & \longrightarrow \mathrm{C}_{6} \mathrm{H}_{5}-\mathrm{N}-\mathrm{N}-\mathrm{C}_{6} \mathrm{H}_{6}+\mathrm{H}_{2} \mathrm{O}
\end{aligned}
$$

The quantity of hydrogen peroxide found in the reaction mixture satisfied the amount required theoretically. The oxidation product of the above substance is orange yellow. That these substances undergo the same type of oxidation as found by Bamberger for hydroxylaminobenzenes is evident from the following considerations. Ten mgm. of the substance (melting point 139.5 to $140.5^{\circ} \mathrm{C}$.) should theoretically require $590 \mathrm{cmm}$. oxygen for complete oxidation. Manometric measurements showed that in two hours time $10 \mathrm{mgm}$. substance consumed 535 to 574 cmm. oxygen (fig. 3), which corresponds to 91.7 to 97.2 per cent of the theoretical figures. Of this, 60 to 82 per cent was recovered as hydrogen peroxide. Evidently part of the hydrogen peroxide is used up in some manner. The oxidation products are orange yellow (Bamberger, Bratten, White and Marshall).

In the presence of catalase or blood the volume of oxygen measured during the oxidation of the above p-hydroxylaminobenzenesulfonamide is about one half of the volume measured in their absence (fig. 3, Ia, $\mathrm{Ib}, \mathrm{Ic})$. This is due to the following reaction:

$$
2 \mathrm{H}_{2} \mathrm{O}_{2}+\text { catalase } \rightarrow 2 \mathrm{H}_{2} \mathrm{O}+\mathrm{O}_{2}
$$

The oxygen liberated returns to the system.

All of our experiments with p-hydroxylaminobenzenesulfonamide showed that about 60 per cent of it is oxidized during the first 30 minutes (fig. 3). For this reason the method proposed by Rosenthal and Bauer (1939) for determining the amount of this substance in the presence of aromatic amines after 30 minutes pretreatment with acetic anhydride cannot be employed. The ease with which this substance is oxidized

the method we used differs from that of Burton. He stated that these are dimorphic forms of the same substance. Our results, as described above, show that these two preparations are chemically and biologically different. 
would make the demonstration of its formation in biological systems likewise difficult.

\section{3. p-Aminobenzenesulfonhydroxamide, 4. Benzenesulfonhydrox- amide, 5. Benzhydroxamic acid}

These substances and their acyl-derivatives have been shown by Moore, Miller and Miller (1940), and Hampil, Webster and Moore (1941) to possess antistreptococcal activity. The studies on the effect of these substances on the aerobic and anaerobic respiration of streptococci (tables 1 and 2) show that they exercise greater inhibition than sulfanilamide.

Properties of the drugs. Of the above three substances the first is oxidizable in air (fig. 3), the other two have been found to be resistant under identical conditions. It was desirable, therefore, that the first substance be introduced in dry form from the side arm into the respiratory system just before the measurements were started. The oxidation product is lemon yellow. According to Piloty (1896) benzenesulfonhydroxamide is oxidized by ferric chloride, hypochlorite, or iodine giving a lemon yellow substance. He proposed the formula of $\left(\mathrm{C}_{6} \mathrm{H}_{5} \mathrm{SO}_{2}\right)_{2} \mathrm{NOH}$ resulting from two molecules of $\mathrm{C}_{6} \mathrm{H}_{5} \mathrm{SO}_{2} \mathrm{NHOH}$ and involving the use of one atom of oxygen. In our experiments $10 \mathrm{mgm}$. of p-aminobenzenesulfonhydroxamide used $190 \mathrm{cmm}$. oxygen during three and one half hours time. Theoretically it should require $300 \mathrm{cmm}$. oxygen. Assuming that the reaction under our conditions follows the course proposed by Piloty we can account for 60 per cent of the oxygen theoretically required. Hydrogen peroxide is not formed during the oxidation of this substance. In anaerobic systems in the presence of $\mathrm{NaHCO}_{3}$ all the above three substances evolved a gas not absorbable by $\mathrm{KOH}$ (fig. 4). Piloty found that benzenesulfonhydroxamide decomposes in $\mathrm{KOH}$ solution yielding $2 \mathrm{C}_{6} \mathrm{H}_{5} \mathrm{SO}_{2}+\mathrm{H}_{2} \mathrm{~N}_{2} \mathrm{O}_{2}$. Under the conditions of our experiment p-aminobenzenesulfonhydroxamide yields a gas. This gas, possibly resulting from the decomposition of $\mathrm{H}_{2} \mathrm{~N}_{2} \mathrm{O}_{2}$, may be assumed to be $\mathrm{N}_{2} \mathrm{O}$ from the fact that $10 \mathrm{mgm}$. $\mathrm{H}_{2} \mathrm{~N}-\mathrm{C}_{6} \mathrm{H}_{4} \mathrm{SO}_{2} \mathrm{NHOH}$ should theoretically yield $593 \mathrm{cmm}$. $\mathrm{N}_{2} \mathrm{O}$. We measured the evolution of $575 \mathrm{cmm}$. gas corresponding to 98 per cent of the amount required by theory. Since the solution of $\mathrm{H}_{2} \mathrm{~N}-\mathrm{OH}$ is stable and does not evolve any gas under identical conditions, it appears that one of the hydrolytic products of the above substance is not 
$\mathrm{H}_{2} \mathrm{~N}-\mathrm{OH}$, and that $\mathrm{N}_{2} \mathrm{O}$ is not derived from $\mathrm{H}_{2} \mathrm{~N}-\mathrm{OH}$ as an intermediary product.

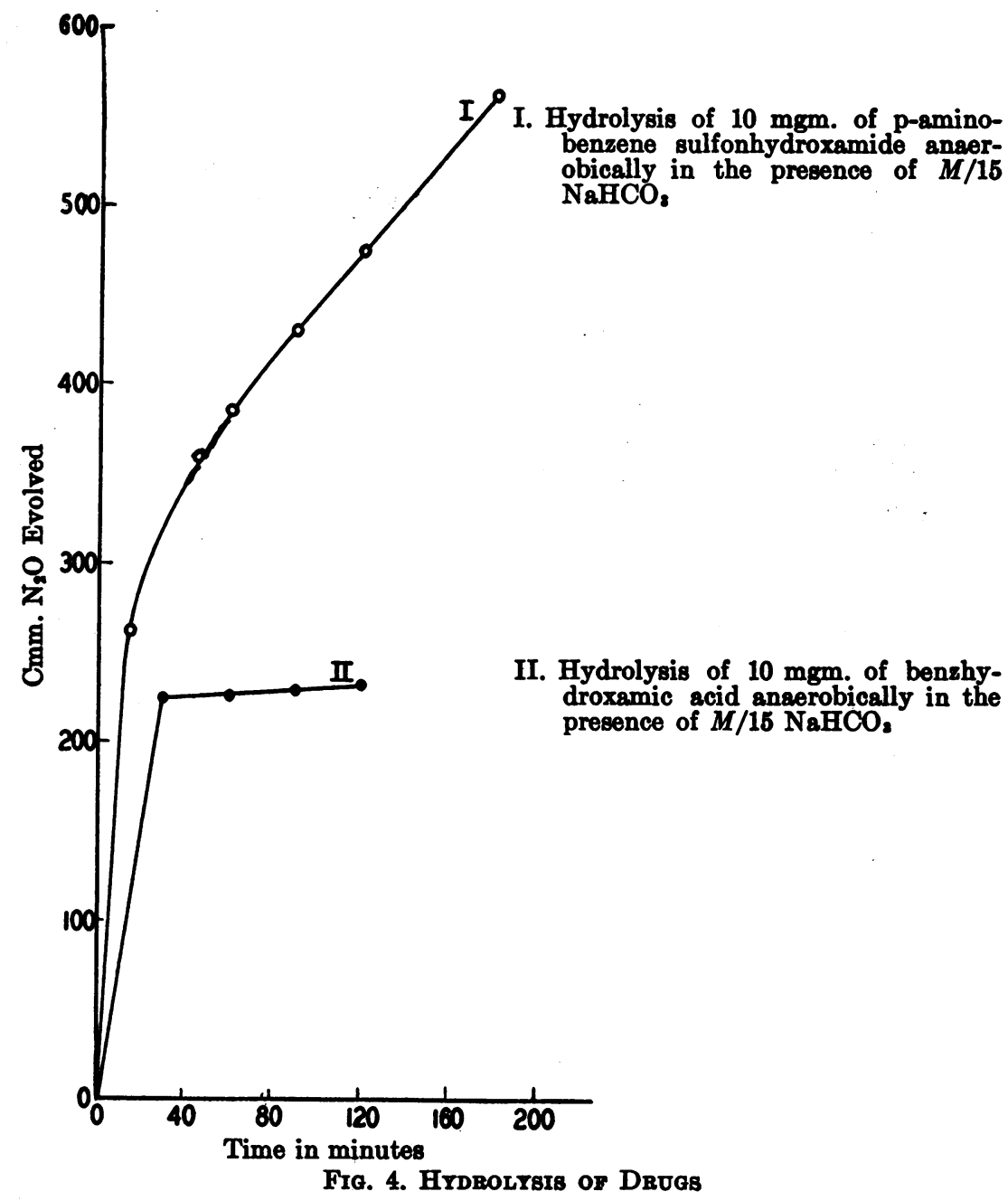

The inhibiting effect of the oxidation products of p-aminobenzenesulfonhydroxamide and the non-gaseous hydrolytic products of the above three substances was tested on respiration. The first was oxidized aerobically for two hours in a Warburg set-up and the 
reaction mixture was then tested on aerobic respiration. It showed slight decrease in the inhibiting effect. Another sample was completely hydrolyzed anaerobically in the presence of $\mathrm{NaHCO}_{3}$ and then tested on anaerobic respiration. The inhibiting effect was completely lost.

\section{Hydroxylamine hydrochloride}

It has been shown that neutral solutions of hydroxylamine exercise powerful inhibiting effect on catalase (Jacobson, 1892; Blaschko, 1935). Smythe (1939) stated that hydroxylamine strongly inhibited yeast fermentation. Frank and Gaffron stated that hydroxylamine inhibited the photosynthetic reactions by plants and bacteria (Frank and Goffron, 1941).

We have found that $\mathrm{H}_{2} \mathrm{NOH}$ in dilutions up to $0.001 \mathrm{M}$ inhibits the respiration of streptococci to a high degree (see tables 1 and 2, footnote $\S$ ).

In our control experiments a neutral,solution of the substance is resistent to air oxidation. It is also stable in the presence of $\mathrm{NaHCO}_{3}$ under anaerobic conditions. In contrast to the resistance of $\mathrm{H}_{2} \mathrm{NOH}$ to oxidation under conditions cited above, it oxidizes in whole blood as will be seen in figure 3, curve III.

\section{DISCUSSION}

The inhibitory action of sulfanilamide drugs on bacterial growth has been the subject of numerous studies. As the processes involved during growth are numerous and complex, no clear insight as to the possible mechanism of the action of these drugs has been gained, as yet. The inhibition of growth by any agent can be assumed to have resulted from the inhibition of one or more of the enzyme systems-respiratory, proteolytic, amylolytic, lipolytic, etc.,- - of growing bacteria. A few studies dealing with this subject have shown that these drugs exercise a slight inhibiting effect on the oxygen uptake of the washed suspensions of certain bacteria in the presence of glucose. The experiments devoted to these studies were limited in number and scope. The experimental conditions were not comparable to the conditions existing during growth in vitro or in vivo. Furthermore, the slight inhibition of 
oxygen uptake has not been correlated with the simultaneous inhibition of growth. For such reasons, perhaps, these findings have not generally received the consideration due them.

The metabolic activity of bacteria in the "resting state" results in oxygen consumption aerobically and the evolution of carbon dioxide anaerobically, in the presence of a substrate such as glucose. During such activity, though the washed cells do not multiply, the degree of their activity indicates potentiality for multiplication when favorable conditions for growth are offered. The respiration of a non-proliferating bacterial suspension can be inhibited by various agents, which likewise may prove to be growth-inhibiting. On the other hand it is a well established fact that the bacteria killed by various bacteriocidal agents do not respire, indicating that there is a direct relation between the effect on the respiration and multiplication, and vice versa.

During the respiration of the "resting state," (and also most probably when multiplication takes place), there is present endogenous activity, involving the oxygen uptake and the evolution of carbon dioxide. The type, age, and the condition under which respiration (and growth) takes place are factors in determining the degree of endogenous activity. In general it is due to the processes of disintegration or oxidative autolysis, for which reason the greater the endogenous activity the smaller the activity in metabolizing a given substrate (Wieland and Sevag, 1933; Sevag, 1933). Killed organisms may consume a small amount of oxygen, or anaerobically reduce methylene blue, or similar dyes, for the reason that reducing substances are liberated from the cells undergoing autolysis. Such substances are also to be found in cell-free culture fluid depending on the extent of the autolysis of the cells grown in it (Avery and Neill, 1924 a, b, c, and d). This, as well as the oxygen consumed during endogenous activity, however, is in no way related to the respiration of the "resting state" of the cells which alone can serve as a potential source of energy utilizable for multiplication.

The present study has concerned itself mainly with the mechanism of sulfanilamide action on the respiration of streptococci, and the various points discussed above have been taken into considera- 
tion in evaluating the results obtained. The measurements were carried out under conditions most favorable for active respiration. The systems contained glucose, yeast extract, with or without serum, or defibrinated whole blood. Under these conditions sulfanilamide, p-hydroxylaminobenzenesulfonamide, p-aminobenzenesulfonhydroxamide, etc., and hydroxylamine hydrochloride exercised strong inhibiting effect on both the aerobic and anaerobic respiration. The inhibition in the presence of a constant amount of sulfanilamide was found to be inversely related to the number of organisms present in the system. The inhibiting effects of 0.04 $M$ sulfanilamide on the aerobic respiration of 4.1, 2.05, and 1.02 mgm. of streptococci were, respectively, 22,31 , and 48 per cent, and anaerobically 11,15 , and 25 per cent. Similarly, varying amounts of sulfanilamide vary in their inhibiting effect on the respiration of a given number of organisms (table 1 and 2). These results are in agreement with the findings of numerous other investigators that the effect on growth is directly related to the concentration of the drug.

Even when minimal amounts of glucose and yeast extract, with or without serum, were present in the respiration system the washed cells respired actively; however, an increase in the number of organisms under these conditions could not be demonstrated. The nutritional conditions were either too limited to allow growth, or the increase in number was too small to be detected. Nevertheless under these conditions all the drugs mentioned above exercise strong inhibition (table 3 ). When the optimal amounts of glucose, yeast extract and serum were added to the respiratory systems the respiration was active and also the increase in the number of organisms could readily be measured (table 4 and figures 1 and 2). The increase in the number of streptococci after 1, 2, and 3 hour periods of aerobic growth was, respectively, 50, 100, 120 per cent; anaerobically the growth was slightly less, but the general trend of growth was of similar nature. The inhibition of the aerobic respiration was, respectively 43.5, 60 and 64 per cent, the inhibition of growth during the corresponding periods was also, respectively, 42,62 , and 67 per cent. Under anaerobic conditions the inhibition of respiration at the end of the 
third hour was 40 per cent, and inhibition of growth 37 percent. These results show that the inhibition of both the aerobic and anaerobic respiration results in proportional inhibition of growth.

During the three hour period of growth about $1.0 \times 10^{7}$ organisms consumed $1 \mathrm{cmm}$. oxygen which corresponds to $2.5 \times 10^{\circ}$ molecules of oxygen consumed per coccus. Similarly a single coccus is responsible for the evolution of $7.3 \times 10^{9}$ molecules of carbon dioxide under anaerobic conditions. Since these values are to be interpreted as a measure of energy relationship of the various reactions involved during growth, the effect of sulfanilamide has been to reduce the production of energy utilizable for growth aerobically by 63 per cent, and anaerobically by 40 per cent.

It has been generally accepted that there is a period of 2 to 6 hours before in vitro effect of a drug on growth becomes apparent (Long and Bliss, 1939; Lockwood, 1938; Osgood, 1938; Spring, et al., 1940). In all of the studies referred to a small initial inoculum has been used to demonstrate the bacteriostatic or bactericidal properties of chemotherapeutic agents in vitro.

In contrast to the above studies Libby (1940) reported that using large inocula (12 to 50 million organisms), in every instance where a drug has shown activity at the four-hour incubation period it has been possible to demonstrate activity at the two-hour incubation period. In all our experiments the initial inoculum has been over a billion organisms. In every instance the drug has had an inhibiting effect on respiration as early as the first quarter or one-half hour period. The measurement of growth taken after the first hour of respiration showed that the inhibition of growth by sulfanilamide was in proportion to the inhibition of respiration. From our findings it would appear that the effect of the drug on growth is exercised as soon as the effect on respiration becomes effective.

For the demonstration of an appreciable inhibition of respiration by sulfanilamide the volume of $\mathrm{O}_{2}$ consumed and $\mathrm{CO}_{2}$ evolved by streptococci, or pneumococci (see Article III), was an important factor to be considered. In systems respiring weakly the inhibition was in general relatively small, and therefore of uncer- 
tain nature. For a system to respire actively, it required 2 to 5 billions of young cocci per test, and therefore a proportionate amount $(0.02$ to $0.04 \mathrm{M})$, of sulfanilamide. The use of this and of higher concentrations of enzyme inhibitors is in accordance with general practice in studies on enzymes (Elvehjem and Wilson, et al. (1939)).

That the inhibiting effect of $0.04 \mathrm{M}$ sulfanilamide on the respiration and growth of streptococci was not dependent on the alteration of the colloidal properties of the cells, or on a possible osmotic concentration effect was evident from the fact that: (a) the degree of inhibition by a given concentration of sulfanilamide was in inverse ratio to the number of cocci, and vice versa; and, also, (b) both the inhibition of respiration and growth were reversible. This reversibility of the inhibition appeared to be responsible, as discussed in Article III, for the anti-sulfanilamide action of p-aminobenzoic acid and possibly of other substances.

\section{SUMMARY}

Our findings show that the aerobic and anaerobic respiration of Streptococcus pyogenes is inhibited by sulfanilamide, hydroxylamine, and its sulfonamide derivatives.

The inhibition of respiration takes place even in the absence of growth. In the presence of growth the inhibition of respiration results in the proportional inhibition of growth.

We are indebted to; Mr. J. Smolens for his valuable contributions, Prof. Stuart Mudd for his interest and helpful suggestions, Drs. R. O. Roblin, Jr. of the American Cyanamid Company, Maurice L. Moore of Sharp and Dohme, W. A. Lott of Squibbs Medical Institute, E. Schwenk of Schering Corporation and J. R. Lucas of Winthrop Chemical Company for supplying some of the chemicals used in this work.

\section{REFERENCES}

Avmry, O. T., AND Nmill, J. M. 1924a Studies on oxidation and reduction by pneumococcus. I. Production of peroxide by anaerobic cultures of pneumococcus on exposure to air under conditions not permitting active growth. J. Exptl. Med., 39: 347-355. 
Averx, O. T., AND Nẹill, J. M. 1924b II. The production of peroxide by sterile extracts of pneumococcus. J. Exptl. Med., 39: 357-366.

Avery, O. T., AND NiILl, J. M. 1924c III. Reduction of methylene blue by sterile extracts of pneumococcus. J. Exptl. Med., 39: 543-552.

AvmRY, O. T., AND NEILL, J. M. 1924d IV. Oxidation of hemotoxin in sterile extracts of pneumococcus. J. Exptl. Med., 39: 745-755.

BAMBmRger, E. 1898 Zur Kenntniss der Nitrosoalphylhydroxylamine. Ber. deut. chem. Ges., 31: 574-589.

Bamberger, E. 1900 Ueber die Oxydation wässriger Arylhydroxylaminlosungen durch den Luftsauerstoff. Ber. deut. chem. Ges., 33: 113-122.

BARroN, E. S. G., AND JACOB, H. R. 1937 Effect of prontosil and prontylin on metabolism of bacteria. Proc. Soc. Exptl. Biol. Med., 37: 10-11.

Braschro, H. 1935 The mechanism of catalase inhibitions. Biochem. J., 29: 2303-2312.

Buss, E. A., AND Long, P. H. 1939 Observation upon the mode of action of sulfanilamide and sulfapyridine. Third International Congress for Microbiology, New York, III, 585-586.

Bratten, A. C., White, H. J., and Marshald, Jr. E. K. 1939 Comparison of certain pharmacological and antibacterial properties of p-hydroxylaminobensenesulfonamide and sulfanilamide. Proc. Soc. Exptl. Biol. Med., 42: 847-853.

BroH-KAHN, R. H. 1939 The bacteriostatic action of sulfanilamide under anaerobic conditions. Science, 90: 543-544.

BURToN, H. 1941 p-Hydroxylaminobenzenesulphonamide, its preparation and dimorphism. Chemistry and Industry, 60: 449.

Cru, H. I., and Hastings, A. B. 1938 The effect of para-aminobenzene-sulfonamide on the oxygen consumption of tissue and certain pathogenic bacteria. J. Pharmacol., 63: 407-413.

Coggmshald, L. T. 1940 The selective action of sulfanilamide on the parasites of experimental malaria in monkeys in vivo and in vitro. J. Exptl. Med., 71: $13-20$.

ELY, J. O. 1939 The evaluation of germicides by the manometric method. J. Bact., 38: 391-400.

Eltmhjem, C. A., Wilson, P. W., ex al. 1939 Respiratory Enzymes, pp. 137155. Burgess Publishing Company, Minneapolis, Minn.

Frank, J., AND Gafrron, H. 1941 Advances in enzymology, p. 248, edited by F. F. Nord and C. H. Werkman, Interscience Publishers, Inc., New York.

Hampil, B., Webster, G. W., and Moorr, M. L. 1941 Chemotherapeutic activity of N4-Acyl-sulfanilhydroxamides. J. Pharmacol., 71: 52-58.

JACoBson, J. 1892 Untersuchungen uber lösliche Fermente. Z. physiol. Chem., 16: 340-369.

Kalmanson, G. M. 1940 The bactericidal power of sulfanilamide under anaerobic conditions. J. Bact., 40: 817-822.

LiBBY, R. L. 1940 The activity of chemotherapeutic agents. J. Bact., 10: 733-745.

Lockwood, J. S. 1938 Studies on the mechanism of the action of sulfanilamide. III. The effect of sulfanilamide in serum and blood on hemoly tic streptococci in vitro. J. Immunol., 35: 155-194. 
Long, P. H., AND Buss, E. A. 1939 The clinical and experimental use of sulfanilamide, sulfapyridine, and allied compounds, pp. 96-110. The Macmillan Co., New York.

Mayer, R. L., and OzChsin, C. 1937 Antistreptococcique; l'activité et le toxicité de corps dérivés de la benzène-sulfamide. Compt. rend., 205: 181-182.

MAyer, R. L., AND OrChsin, C. 1937a Recherches sur le mécanisme de l'action antistreptococcique de l'aminobenzènesulfamide et de ses dérivés. Bull. acad. méd., 117: 727-735.

Mayer, R. L., and Orschin, C. 1937b Chimiothérapie expérimentale des infections streptococcique. Activité de la septazine et de la saluseptazine. Biol. méd. Paris (Supp.), 27 : 45-73.

MAyer, R. L. 1939 Essais de chimiothérapie du tetanos. Actions des sulfamides sur le bacille tétanique pur et sur sa toxine. Compt. rend. soc. biol., 130: 1560-1562.

Moore, M. L., Miller, C. S., AND MrLler E. 1940 Substituted sulfanilamides. III. N4-Acyl-N'-hydroxy Derivatives. J. Am. Chem. Soc., 62: 20972099.

OsGood, E. E. 1938 Culture of human marrow: Studies on the mode of action of sulfanilamide. J. Am. Med. Assoc., 110: 349-356.

PiLoty, O. 1896 Uteber eine Oxydation des Hydroxylamins durch Benzolsulfochlorid. Ber. deut. chem. Ges., 29: 1559-1567.

Rosenthal, S. M., and BAUER, H. 1939 Studies in chemotherapy; colorimetric tests for aromatic hydroxylamines and for further oxidation products of aromatic amines. Their demonstration in urine following sulfanilamide administration. U. S. Pub. Health Repts., 54: 1880-1890.

SevaG, M. G. 1933 Uber die Beziehungen zwischen enzymatischer Aktivität, Morphologie und Färbarkeit von Buttersäurebakterien und über den Mechanismus der Restatmung. Z. Hyg. Infektionskrankh., 114: 756-768.

Smythe, C. V. 1939 Effect of certain tissue extracts, of ammonium salts, and certain amides on the rate of fermentation by baker's yeast. Enzymologia, 6: 9-14.

Spring, W. C., Lowell, JR. F. C., ANd Finland, M. 1940 Studies on the action of sulfapyridine on pneumococci. J. Clin. Investigation, 19: 163-177.

Wimland, H., and Sevag, M. G. 1933 Uber den Mechanismus der Oxydationsvorgänge. 33. Dehydrierungsreaktionen mit Buttersäurebakterien. Ann. Chemie., 601: 151-62. 